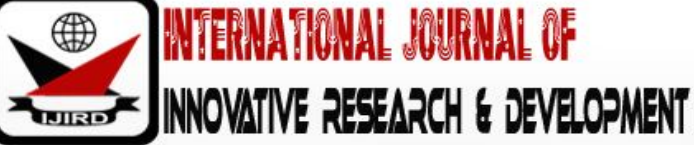

ISSN 2278 - 0211 (Online)

\section{Quality of Work Life and Affective Commitment: A Study of Blue-Collar Employees in Northern Malaysia}

Ali Yusob Md Zain
Associate Professor, School of Business Management, University Utara Malaysia, Malaysia
Hesri Mintawati
Ph.D. Student, School of Business Management, University Utara Malaysia, Malaysia
Mohd Sobri Minai
Professor, School of Business Management, University Utara Malaysia, Malaysia

\begin{abstract}
:
This study examines the relationships between quality of work life (QWL) and affective organizational commitment. A random sample of 273 blue-collar employees from fifty private sector organizations in northern Malaysia responded to the survey questionnaire. The seven dimensions QWL scale, and the affective organizational commitment scale were used to collect the data. The data was analysed by using the Smart PLS software for the measurement and the structural models. The measurement model analysis indicates that all the scales used in this study show acceptable levels of composite reliability, convergent and discriminate validities. Results of structural model analysis indicate that six of the QWL dimensions are significantly related to affective commitment. Supervision is the only QWL dimension which is not significantly related to affective commitment. Implications of the findings and suggestions for further research also discussed.
\end{abstract}

Keywords: quality of work life, affective commitment, Malaysia, blue-collar employees

\section{Introduction}

The ability of an organization to sustain its competitive advantage depends on its human capital who are committed to the organization's goals. However, high employee turnover rate poses a major challenge to many organizations in Malaysia. Goh (2012) states that "job hopping" has become a trend among workforce in Malaysia. A theoretical perspective to explain people's attachment or commitment to an organization is by applying the social exchange theory. Blau and Baul (1987)in their conception of social exchange maintains that individuals enter into and maintain a relationship in a social system as long as they can satisfy their self-interests and at the same time ensure that the benefits outweigh the costs. Based on the social exchange theory to understand employees' commitment to the organization, this paper examines the relationships between quality of work life (QWL)and employees' affective commitment.

Organizational commitment, as a management concept, has gained considerable interest from management scholars since the 80's. Organizations have devised various policies, especially policies that are related to human resource management, to maximize employee commitment in order to achieve positive organizational outcomes such as innovativeness and creativity (Xerri\& Brunetto, 2013).

Meyer and Allen (1991) proposed a model of organizational commitment by defining it in terms of three dimensions, namely affective, continuance and normative. Affective commitment refers to the desire of employees to remain in the organization as a result of positive attitudes that develop from their experiences with the organization. Continuance or calculative commitment is the need of employees to maintain membership based on their calculative considerations, such as the costs associated with leaving the organization, and the perceived lack of alternatives elsewhere. The third dimension, normative commitment refers to the feeling of obligation of employees to maintain organizational membership resulting from internalization of a loyalty norm (Wahab et al., 2009).

This paper is an attempt to examine the influence of employees' perceived experience in their organizations (using the variable quality of work life, QWL) on their affective organizational commitment. The employees selected to participate in this study were blue-collar employees of private sector organizations in the northern states of Malaysia.

\subsection{Affective Commitment}

The term affective commitment is used to describe the sense of affective attachment that an individual has towards the organization, which is referred to as "cohesion commitment" by several authors (Kanter, 1968; Huddy, 2013; Dixit\& Bhati, 2012), and it is a partisan, affective attachment to the goals and values, and to the organization for its own 
sake, apart from its instrumental worth (Buchanan 1974; Wasti, 2002). Greenberg (1999) argued that affective commitment is the "strength of people's desires to continue working for an organization because they agree with its underlying goals and values".

Yu and Egri (2005) suggested that the determinants of organizational commitment can be classified into three categories: personal (job expectations, job values, and motivations); job related (job security, co-worker support, and promotional opportunities); and environmental (job opportunities). Other factors which were found to demonstrate positive relationships with affective commitment include: leader-member exchange, supervisor's organizational embodiment (Eisenberger et al., 2010); job satisfaction (Yücel, 2012); organizational learning culture (Joo, 2010); and psychological ownership (Han, Chiang\& Chang,2010).

Some of the consequences of organizational commitment mentioned in the literature are: decreased turnover intentions, employee burnout and absenteeism, and increased extra-role behaviours, acceptance of a change, innovation and flexibility (Yu\& Egri, 2005; Iverson, 1996). High organizational commitment also contributes to better job performance (Chughtai \& Zafar, 2006), higher productivity (Westover, Westover, \& Westover(2010) and higher levels of organizational citizenship behaviour (Meyer et al., 2002; Zeinabadi \& Salehi,2011).

\subsection{Quality of Work Life (QWL)}

The phrase "quality of work life" was first introduced in the United States in the late 1960's to address the problems of poor quality of life at the workplace(Davis, 1977).The concern with quality of work life originated from a series of studies carried out by Trist and his co-workers at the Tavistock Institute in London. The findings of these studies serve as the foundations for the socio technical systems theory on which many current efforts to reform work organizations are based (HuseandCummings,1985).

QWL as a variable is employed as an overall term for outcomes from a job (Cotton, 1993).From this perspective, QWL can be described as "the degree of excellence in work and working conditions, which contributes to the overall satisfaction of the individual and enhances individual as well as organisational effectiveness" (Sayeed and Sinha, 1981).Taylor and Bowers (1972) refer to it as the "phenomenological experience of people at work", focusing primarily on the quality of working life from the perspective of the individual employee.

The definitionbyGuest(1979)isprobablythemostrepresentativeofthisperspective.AccordingtoGuest" "qualityofwork lifeisagenericphrasethatcoversaperson'sfeelingsabouteverydimensionofworkincludingeconomicrewardsandbenefits,secur ity,workingconditions,organisationalandinterpersonalrelationships,anditsintrinsicmeaninginaperson'slife".

\section{Methodology}

\subsection{Sample and Procedure}

Participants for this study were 273 blue-collar employees (those who are not required to perform any supervisory duties in their jobs) employed by private sector organizations in northern Malaysia. Fifty organizations were invited and agreed to take part in the data collection. Ten set of questionnaires were mailed to each organization for distribution to randomly selected blue-collar employees i.e. a total of 500 sets of self-administered questionnaires were distributed. 273 usable questionnaires were returned by the respondents, constituting an effective response rate of $54.6 \%$. All questionnaires were self-administered, respondents were requested to return the completed questionnaires by using the postage-paid envelopes provided by the researchers, attached together with the survey questionnaires. They were assured of confidentiality.

\subsection{Measures}

\subsubsection{Quality of Work Life}

We used 21 items taken from the instrument developed by Md Zain (1996) to measure quality of work life (QWL). Based on Md Zain (1996), QWL has seven dimensions:

a) Growth and development (sample item: My job provides sufficient opportunities for my growth and development)

b) Participation opportunities(sample

Myorganisationprovidesopportunitiesformetogivemyideasandsuggestionstomysupervisor)

c) Physical environment (sample item: The physical surroundings of this organisation are good)

d) Supervision (sample item: (My supervisor has confidence in my abilities)

e) Pay and benefits (sample item: The pay system in this organisation is based on merit)

f) Social relevance (sample item:Myw orkinthisorganisationallowsmetopursueotherinterestsinlife)

g) Workplace integration (sample item: Employees in this organisation work together as a team)

Ratings were completed on a five-point Likert scale ranging from 1 (strongly disagree) to 5 (strongly agree).

\subsubsection{Affective Organizational Commitment}

Affective commitment was assessed using an eight-item scale developed by Meyer and Allen (1991). This scale measures the affective component organizational commitment. Ratings were completed on a five-point scale ( $1=$ Strongly disagree to $5=$ Strongly agree). Sample items: "I would be happy to spend the rest of my career with this organisation"; and "This organisation has personal meaning for me". 


\section{Results}

\subsection{Sample Characteristics}

The demographic characteristics of the sample who participated in this study are presented in Table 1. From the table it can be seen that most of the respondents are: female (59.0\%), with the majority of them in the age group of 35 years or less (86.5\%) and have three years or less of organizational membership (59.0\%).

\subsection{The Measurement Model}

The measurement model analysis was conducted using the PLS-SEM to assess the reliability and the validity (convergent and discriminant) of the measurements used in this study. The results of the analysis are shown in Figure 1.

\subsubsection{Reliability and Convergent Validity}

PLS-SEM analysis using SmartPLS was used to evaluate the measurement model developed for this study. As suggested by Anderson and Gerbing (1988), two stages of the SEM analysis were conducted. The first stage provides results related to internal reliability and convergence validity, and the second stage provides assessment on the discriminant validity of the constructs in the model.

\begin{tabular}{|c|c|c|}
\hline Variable & Frequency (N=273) & $\mathbf{\%}$ \\
\hline Gender & 112 & 41.0 \\
1. Male & 161 & 59.0 \\
2.Female & 122 & 44.7 \\
Age group & 114 & 41.8 \\
1.25 yrs. or less & 37 & 13.6 \\
2.226 -35 years & & \\
36 years and above & 161 & 59.0 \\
Length of service & 42 & 15.4 \\
1. 3 years or less & 11 & 4.0 \\
2. 4 - years & 18 & 6.6 \\
3. 7- years & 41 & 15.0 \\
4. 10 - 12 years & & \\
5. 12 years or more & & \\
\hline
\end{tabular}

Table 1: Demographic Characteristics of Respondents

Hair et al., (2017) state that there are three criteria which are used to assess the measurement model: the first is the composite reliability measure which assess the internal consistency of measurement, the second is the indicator reliability, and the third criteria is the average variance extracted which indicates the convergent validity. Nunally and Bernstein (1994) suggest that a composite reliability score of between 0.70 and 0.90 is satisfactory.

Convergent validity refers to the extent to which a scale demonstrates positive correlation with an alternative scale measuring the same construct (Hair et al., 2017).This is assessed by examining an item loading on the construct and the average variance extracted (AVE). Acceptable level for item loading is 0.70 , and for AVE is 0.50 . Results of the internal reliability and convergent validity analysis are shown in Table 2 . The results show that the composite reliabilities of all the scales exceed 0.70 , and all the values of AVE are more than 0.50 , indicating that the scales used in this study have adequate reliability and convergent validity scores. 


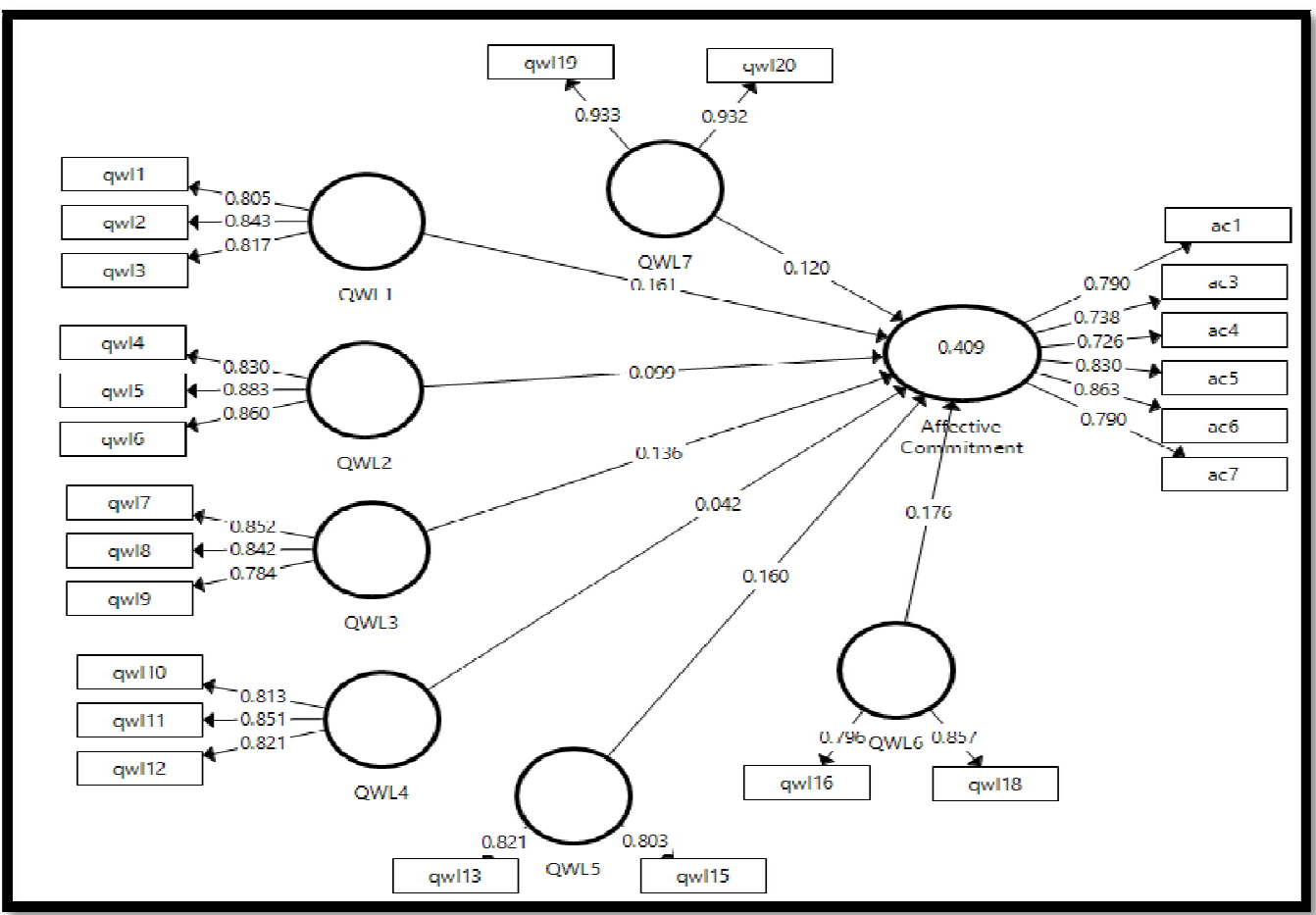

Figure 1: Measurement Model - Quality of Work Life and Affective Commitment

\begin{tabular}{|l|c|c|}
\hline \multicolumn{1}{|c|}{ Scale } & Composite reliability & AVE \\
\hline Affective commitment (AC) & .909 & .625 \\
\hline Growth and development (QWL1) & .862 & .675 \\
\hline Participation (QWL2) & .893 & .736 \\
\hline Physical environment (QWL3) & .866 & .683 \\
\hline Supervision (QWL4) & .868 & .687 \\
\hline Pay and benefits (QWL5) & .795 & .660 \\
\hline Social relevance (QWL6) & .812 & .684 \\
\hline Workplace integration (QWL7) & .930 & .869 \\
\hline
\end{tabular}

Table 2: Construct Reliability of Scales

\subsubsection{Discriminant Validity}

Discriminant validity refers to the extent to which a construct is different from other constructs by using empirical standards (Hair et al., 2017). Three approaches are used to examine the discriminant validity. The first approach is by examining the cross loadings of items with the constructs, the second approach uses the Fornell-Larcker criteria, and the third approach employs the heterotrait-monotrait ratio of correlations (HTMT). Hair et al., (2017) provide the following guidelines for assessing discriminant validity:

- The outer loadings of items measuring a particular construct should be higher than their loadings on other constructs.

- In the Fornell-Larcker criteria, the square root of the AVE of a construct is compared with its correlations with the other constructs. Discriminant validity is considered to be present when the square root of the AVE of the construct is higher than its correlations with the other constructs.

- In the HTMT approach, the discriminant validity is present when the correlations between constructs are less than 0.90 .

\subsubsection{Item-Construct Cross Loadings}

Results of item-construct cross loadings are shown in Table 3. The results show that the items have the highest loadings on the constructs they are supposed to measure. The cross loadings of the items on other constructs are lower than the loadings on their respective constructs, for example the loadings of ac1 - ac7 are highest on the affective commitment (AC) construct which the items are supposed to measure. Based on these item-construct cross loadings, we are able to conclude that the constructs used in this study possess acceptable levels of discriminant validity. 


\begin{tabular}{|c|c|c|c|c|c|c|c|c|}
\hline & AC & QWL1 & QWL2 & QWL3 & QWL4 & QWL5 & QWL6 & QWL7 \\
\hline ac1 & 0.79 & 0.423 & 0.358 & 0.354 & 0.374 & 0.438 & 0.41 & 0.407 \\
\hline ac3 & 0.738 & 0.331 & 0.324 & 0.344 & 0.33 & 0.318 & 0.37 & 0.348 \\
\hline ac4 & 0.726 & 0.31 & 0.3 & 0.248 & 0.251 & 0.311 & 0.298 & 0.32 \\
\hline ac5 & 0.83 & 0.376 & 0.401 & 0.345 & 0.373 & 0.362 & 0.396 & 0.39 \\
\hline ac6 & 0.863 & 0.35 & 0.386 & 0.339 & 0.349 & 0.403 & 0.358 & 0.366 \\
\hline ac7 & 0.79 & 0.41 & 0.37 & 0.371 & 0.357 & 0.351 & 0.393 & 0.379 \\
\hline qwl1 & 0.401 & 0.805 & 0.395 & 0.31 & 0.422 & 0.344 & 0.381 & 0.383 \\
\hline qwl10 & 0.382 & 0.391 & 0.43 & 0.296 & 0.813 & 0.285 & 0.321 & 0.374 \\
\hline qwl11 & 0.341 & 0.393 & 0.482 & 0.392 & 0.851 & 0.343 & 0.275 & 0.579 \\
\hline qwl12 & 0.35 & 0.396 & 0.504 & 0.412 & 0.821 & 0.431 & 0.268 & 0.503 \\
\hline qwl13 & 0.384 & 0.285 & 0.308 & 0.325 & 0.339 & 0.821 & 0.312 & 0.313 \\
\hline qwl15 & 0.368 & 0.339 & 0.423 & 0.35 & 0.35 & 0.803 & 0.327 & 0.421 \\
\hline qwl16 & 0.358 & 0.386 & 0.301 & 0.267 & 0.262 & 0.274 & 0.796 & 0.285 \\
\hline qwl18 & 0.42 & 0.437 & 0.295 & 0.357 & 0.313 & 0.37 & 0.857 & 0.413 \\
\hline qwl19 & 0.439 & 0.396 & 0.501 & 0.385 & 0.546 & 0.421 & 0.412 & 0.933 \\
\hline qwl2 & 0.356 & 0.843 & 0.412 & 0.254 & 0.409 & 0.321 & 0.441 & 0.368 \\
\hline qwl20 & 0.434 & 0.38 & 0.515 & 0.385 & 0.538 & 0.418 & 0.384 & 0.932 \\
\hline qwl3 & 0.39 & 0.817 & 0.361 & 0.179 & 0.339 & 0.278 & 0.411 & 0.276 \\
\hline qwl4 & 0.401 & 0.419 & 0.83 & 0.296 & 0.529 & 0.343 & 0.341 & 0.439 \\
\hline qwl5 & 0.381 & 0.419 & 0.883 & 0.388 & 0.488 & 0.416 & 0.32 & 0.503 \\
\hline qwl6 & 0.384 & 0.381 & 0.86 & 0.344 & 0.443 & 0.397 & 0.262 & 0.461 \\
\hline qwl7 & 0.345 & 0.243 & 0.342 & 0.852 & 0.338 & 0.365 & 0.274 & 0.347 \\
\hline qwl8 & 0.332 & 0.253 & 0.364 & 0.842 & 0.4 & 0.357 & 0.289 & 0.397 \\
\hline qwl9 & 0.372 & 0.252 & 0.285 & 0.784 & 0.353 & 0.308 & 0.373 & 0.285 \\
\hline
\end{tabular}

Table 3: Item Cross Loadings

Note: Highest Loadings of the Items Are in Bold

\subsubsection{Fornell-Larcker criterion}

Table 4 shows the results of discriminant validity analysis using the Fornell-Larcker criteria. The results show that the correlations between construct are smaller than the AVE. This indicates that the measurement model has achieved a satisfactory level of discriminant validity (Hair et al., 2017; Fornell \& Larcker, 1981).

\begin{tabular}{|c|c|c|c|c|c|c|c|c|}
\hline & AC & QWL1 & QWL2 & QWL3 & QWL4 & QWL5 & QWL6 & QWL7 \\
\hline AC & 0.791 & & & & & & & \\
\hline QWL1 & 0.467 & 0.822 & & & & & & \\
\hline QWL2 & 0.453 & 0.474 & 0.858 & & & & & \\
\hline QWL3 & 0.425 & 0.302 & 0.399 & 0.826 & & & & \\
\hline QWL4 & 0.433 & 0.475 & 0.568 & 0.44 & 0.829 & & & \\
\hline QWL5 & 0.464 & 0.383 & 0.448 & 0.415 & 0.424 & 0.812 & & \\
\hline QWL6 & 0.472 & 0.499 & 0.359 & 0.381 & 0.349 & 0.393 & 0.827 & \\
\hline QWL7 & 0.468 & 0.416 & 0.545 & 0.413 & 0.581 & 0.45 & 0.427 & 0.932 \\
\hline
\end{tabular}

Table 4: Fornell-Larcker Criterion of Discriminant Validity

Note: AVE in Bold, the Rest are Correlations

\subsubsection{Heterotrait-Monotrait (HTMT) Method}

Table 5 presents the results of discriminant validity analysis using the HTMT approach. Results of the analysis show that all the correlations between the constructs are less than 0.90 , indicating the presence of discriminant validity for all the dimensions of the measurements used in this study(Henseler, Ringle \& Sarstedt, 2015). 


\begin{tabular}{|c|c|c|c|c|c|c|c|c|}
\hline & AC & QWL1 & QWL2 & QWL3 & QWL4 & QWL5 & QWL6 & QWL7 \\
\hline AC & & & & & & & & \\
\hline QWL1 & 0.566 & & & & & & & \\
\hline QWL2 & 0.531 & 0.600 & & & & & & \\
\hline QWL3 & 0.512 & 0.394 & 0.505 & & & & & \\
\hline QWL4 & 0.519 & 0.619 & 0.714 & 0.575 & & & & \\
\hline QWL5 & 0.705 & 0.631 & 0.714 & 0.683 & 0.697 & & & \\
\hline QWL6 & 0.678 & 0.777 & 0.539 & 0.581 & 0.534 & 0.761 & & \\
\hline QWL7 & 0.539 & 0.518 & 0.653 & 0.514 & 0.723 & 0.704 & 0.622 & \\
\hline
\end{tabular}

Table 5: Heterotrait-Monotrait Ratio (HTMT) of Discriminant Validity

\subsection{The Structural Model}

The main objectives of the structural model analysis is to examine the relationships between the QWL dimensions and affective commitment, i.e the relationships between: QWL1, QWL2, QWL3, QWL4, QWL5, QWL6 and QWL 7 with AC (affective commitment). The results of the structural model analysis is shown in Figure 2.The dimensions of QWL jointly explain about $41 \%$ of variance in affective commitment $\left(\mathrm{R}^{2}=0.409\right)$

Based on the results of PLS-SEM analysis, it was found that six of the QWL dimensions are significantly related to affective commitment. The six dimensions are:

- QWL1 (growth and development; $\beta=0.161, \mathrm{p} \leq .001$ )

- QWL2 (participation opportunities; $\beta=0.099, \mathrm{p} \leq .05$ )

- $\quad$ QWL3 (physical environment; $\beta=0.136, p \leq .001$ )

- QWL5 (pay and benefits; $\beta=0.160, \mathrm{p} \leq .001$ )

- QWL6 (social relevance; $\beta=0.176, \mathrm{p} \leq .001$ )

- $\quad$ QWL7 (workplace integration; $\beta=0.120, \mathrm{p} \leq .01$ )

The only dimension ofQWL which is not significantly related to affective commitment is QWL4 (supervision; $\beta=0.042$, $\mathrm{p}>0.05$ ).

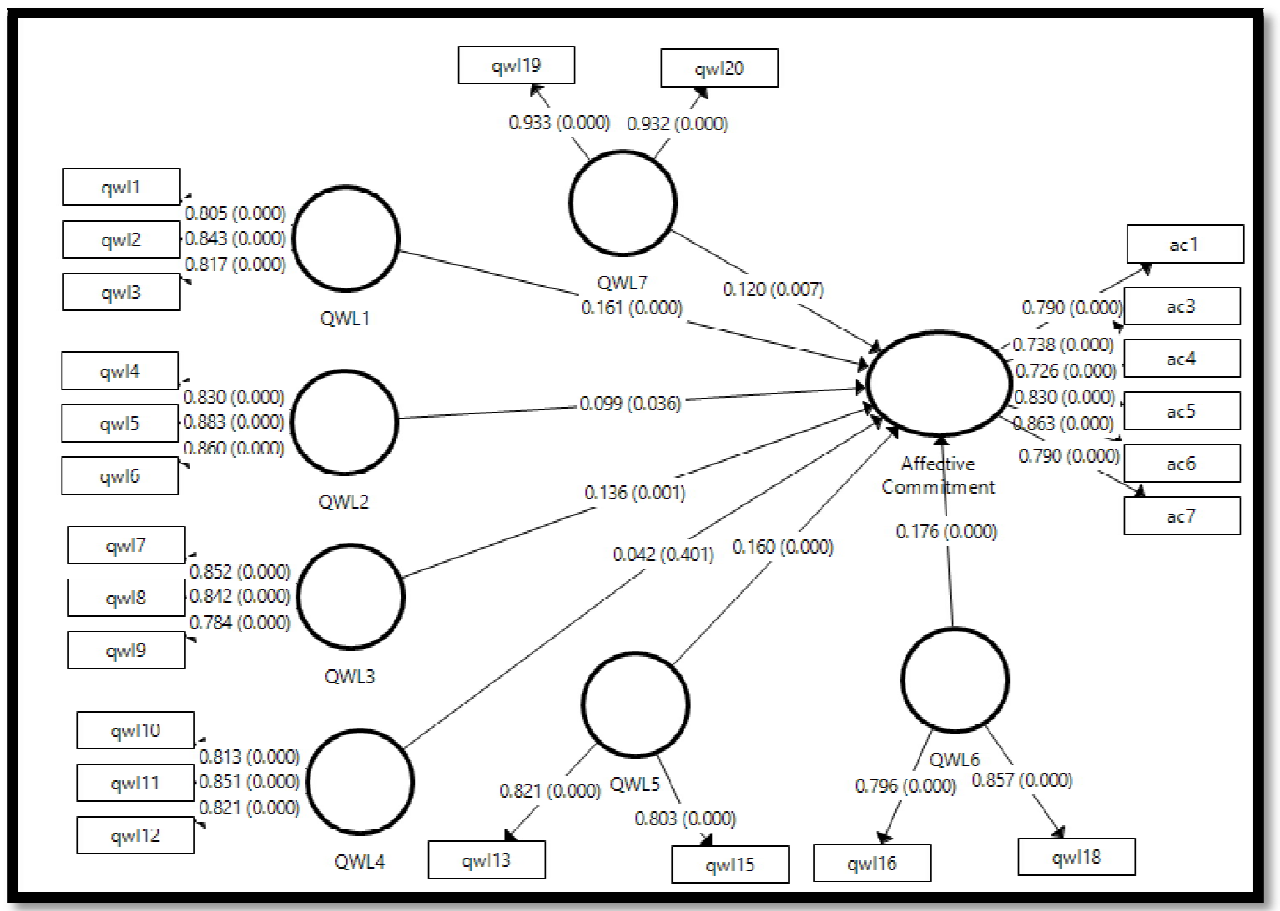

Figure 2: Structural Model: The Relationships between QWL and Affective Commitment

\section{Conclusions and Discussions}

This study is an attempt to explain employees affective organizational commitment among blue-collar employees in Malaysia. This is done by examining its relationships with quality of work life. In view of the increasing competitiveness of the business environment, organizations need to constantly examine their own human capital so that their commitment to the goals of the organizations could be enhanced.

The business environment which is rapidly changing exerts pressures on organizations to take the necessary steps to enhance the performance of their workforce. One of the options which could be considered is to improve the quality of work life in organizations so that employees become more committed, motivated and productive. Based on the findings of 
this study, it is suggested that employers should consider the following initiatives to improve the QWL and consequently, the commitment levels of their blue-collar or operational level employees:

- Opportunities for employees growth and development. These opportunities help employees to gain new knowledge and skills to face new challenges. These opportunities serve as a form of recognition to employees and help to inculcate a sense of belonging among them.

- Participation in decision making process. To improve commitment, organizations need to explore mechanisms to allow for employees' participation in decision making. The importance of participation has also been recognised by a number of authors, for example Dicke (2006) argued that "employees engaged in the company's decisionmaking were more productive, customer-focused, profitable and more willing to stay and develop within the organization".

- Pay and benefits. An organization's compensation system may influence the workers' desire to stay with the organization. The crucial role of compensation in employment decisions has beenclearly articulated in the management literature, for example Riggio (2013) stated that "workers are motivated by money and material gains". Organizations need to have a fair and equitable compensation system so as to promote commitment (Munap, Mohd \& Abdul, 2013).

- Physical working environment. Organizations should always be committed to providing a safe and conducive work environment for their employees. High levels of employee commitment could be achieved by providing an environment which facilitates employees' personal as well as social needs. According to some authors, physical environment is a tool that can be leveraged both to improve business results (Mohr, 1996) and employee wellbeing (Huang, Robertson, \& Chang, 2004).

- Social relevance.Organizations need to consider the pressures that work has on other aspects of employees life. There is a need for organizations to have programs to achieve what is known as "work-life balance", i.e."satisfaction and good functioning at work and at home, with a minimum of role conflict" (Clark, 2000).

- Workplace integration. With increasing diversity in today's organizations, more efforts aimed at achieving integration need to be explored. These efforts are necessary to make the employees feel included, valued and rewarded. It has been suggested that such employeesare more engaged and motivated. It was also found that creating an inclusive and harmonious environment was a key driver in employee engagement and commitment (National Integration Working Group for Workplaces, n.d).

It should also be noted that this study was confined tothe northern states of Malaysia only, thus its findings may not be generalizable to other regions in Malaysia where employees may be exposed to different economic conditions. In order to achieve better generalizability, it is suggested that future studies include respondents from other regions in Malaysia and may also include different levels of employment.

\section{References}

i. Blau, G. J., \& Boal, K. B. (1987). Conceptualizing how job involvement and organizational commitment affect turnover and absenteeism. Academy of Management Review, 12(2), 288-300.

ii. Chughtai, A. A., \& Zafar, S. (2006). Antecedents and consequences of organizational commitment among Pakistani university teachers.Applied H.R.M. Research, 11(1), 39-64

iii. Clark, S. C. (2000). Work/ family border theory: a new theory of work/ family balance. Human Relations, 53(6), 747-70.

iv. Cotton, J. L. (1993). Employee involvement: Methods for improving performance and work attitudes. Sage Publications, Inc.

v. Davis, L. E. (1977). Enhancing the quality of working life: developments in the United States. International Labor Review, 116, 53.

vi. Dicke, C. (2006). Employee engagement and change management.New York: CAHRS.

vii. Dixit, V., \& Bhati, M. (2012). A study about employee commitment and its impact on sustained productivity in Indian auto-component industry. European journal of business and social sciences, 1(6), 34-51.

viii. Eisenberger, R., Karagonlar, G., Stinglhamber, F., Neves, P., Becker, T. E., Gonzalez-Morales, M. G., \& SteigerMueller, M. (2010). Leader-member exchange and affective organizational commitment: The contribution of supervisor's organizational embodiment. Journal of Applied Psychology, 95(6), 1085.

ix. Fornell, C., \& Larcker, D. F. (1981). Structural equation models with unobservable variables and measurement error: Algebra and statistics. Journal of Marketing Research, 382-388.

x. Goh, L. (2012, February 19). Why job-hoppers hop. The Star Online. Retrieved August 3, 2017, from https:/ / www.thestar.com.my/ news/ nation/ 2012/ 02/ 19/ why-jobhoppers-hop/

xi. Greenberg, J. (1999). Managing behavior in organizations. Upper Saddle River, NJ: Prentice Hall.

xii. Guest, R. H. (1979). Quality of work life, learning from Tarrytown. Harvard University Graduate School of Business Administration.

xiii. Hair Jr, J. F., Sarstedt, M., Ringle, C. M., \& Gudergan, S. P. (2017). Advanced issues in partial least squares structural equation modeling. SAGE Publications.

xiv. Han, T. S., Chiang, H. H., \& Chang, A. (2010). Employee participation in decision making, psychological ownership and knowledge sharing: mediating role of organizational commitment in Taiwanese high-tech organizations. The International Journal of Human Resource Management, 21(12), 2218-2233.

xv. Henseler, J., Ringle, C. M., \& Sarstedt, M. (2015). A new criterion for assessing discriminant validity in variancebased structural equation modeling. Journal of the Academy of Marketing Science, 43(1), 115-135. 
xvi. Huang, Y. H., Robertson, M. M., \& Chang, K. I. (2004). The role of environmental control on environmental satisfaction, communication, and psychological stress: effects of office ergonomics training. Environment and Behavior, 36(1), 617-638.

xvii. Huddy, L. (2013). From group identity to political cohesion and commitment. Oxford handbook of political psychology, 737-773.

xviii. Huse, E. F., \& Cummings, T. G. (1985). Organization development and change. West Publishing Company.

xix. Iverson, R. D. (1996). Employee acceptance of organizational change: the role of organizational commitment. International Journal of Human Resource Management, 7(1), 122-149.

xx. Joo, B. K. (2010). Organizational commitment for knowledge workers: The roles of perceived organizational learning culture, leader-member exchange quality, and turnover intention. Human Resource Development Quarterly, 21(1), 69-85.

xxi. Kanter, R. M. (1968). Commitment and social organization: A study of commitment mechanisms in utopian communities. American Sociological Review, 499-517.

xxii. Md Zain, A. Y. (1996). Quality of work life and organisational commitment: A study of non-supervisory employees in Malaysian organisations. PhD Thesis, University of Strathclyde, Glasgow, UK.

xxiii. Meyer, J. P., \& Allen, N.J. (1991). A three-component conceptualization of organizational commitment. Human Resource Management Review, 1(1), 61-89.

xxiv. Meyer, J. P., Stanley, D. J., Herscovitch, L., \& Topolnytsky, L. (2002). Affective, continuance, and normative commitment to the organization: A meta-analysis of antecedents, correlates, and consequences. Journal of Vocational Behavior, 61(1), 20-52.

xxv. Mohr, R. (1996). Office Space is a Revenue Enhancer, Not an Expense. National Real Estate Investor, 38(7), 46-47.

xxvi. Munap, R. Mohd, B. M. I., \& Abdul, R. B. (2013). Organizational reward System and workers' satisfaction at Telekom Malaysia Berhad. Journal of educational and social research, 3(3), 81-288.

xxvii. National Integration Working Group for Workplaces. (n.d).Managing workplace diversity: A toolkit for organisations from https:/ / www.mom.gov.sg/ / media/ mom/ documents/ employmentpractices/wdm/ workplace\%20diversity\%management \%20tookit\%20and\%20managers\%20guide.pdf

xxviii. Nunnally, J. C., \& Bernstein, I. H. (1994). Psychometric Theory (McGraw-Hill Series in Psychology) (Vol. 3). New York: McGraw-Hill.

xxix. Riggio, R. E. (2013). Introduction to Industrial / Organizational Psychology (6th ed.). New Jersey, US: Pearson Education.

xxx. Riketta, M. (2002). Attitudinal organizational commitment and job performance: a meta-analysis. Journal of Organizational Behavior: The International Journal of Industrial, Occupational and Organizational Psychology and Behavior, 23(3), 257-266.

xxxi. Sayeed,O.B.,andSinha,P.(1981).QualityofWorkingLifeinRelationtoJobSatisfactionandPerformanceinTwoOrganizati ons.ManagerialPsychology, 2, 15-30.

xxxii. Taylor,J.C.,andBowers,D.G.(1972).SurveyofOrganizations:AMachineScoredStandardizedQuestionnaireInstrument. AnnArbor:UniversityofMichigan.

xxxiii. Wahab, E., Quaddus, M., Quaddus, M. Nowak, M., \& Nowak, M. (2009, May). Perceived Organizational Support and Organizational commitment: A study of medium enterprises in Malaysia. In International Conference on Human Capital Development (ICONHCD 2009) (Vol. 25, p. 27).

xxxiv. Wasti, S. A. (2002). Affective and continuance commitment to the organization: Test of an integrated model in the Turkish context. International Journal of Intercultural Relations, 26(5), 525-550.

xxxv. Westover, J. H., Westover, A. R., \& Westover, L. A. (2010). Enhancing long-term worker productivity and performance: The connection of key work domains to job satisfaction and organizational commitment. International Journal of Productivity and Performance Management, 59(4), 372-387.

xxxvi. Xerri, M. J., \& Brunetto, Y. (2013). Fostering innovative behaviour: The importance of employee commitment and organisational citizenship behaviour. The International Journal of Human Resource Management, 24(16), 31633177.

xxxvii. Yu, B. B., \& Egri, C. P. (2005). Human resource management practices and affective organizational commitment: A comparison of Chinese employees in a state-owned enterprise and a joint venture. Asia Pacific Journal of Human Resources, 43(3), 332-360.

xxxviii. Yücel, İ. (2012). Examining the relationships among job satisfaction, organizational commitment, and turnover intention: An empirical study. International Journal of Business and Management, 7(20), 44.

xxxix. Zeinabadi, H., \& Salehi, K. (2011). Role of procedural justice, trust, job satisfaction, and organizational commitment in Organizational Citizenship Behavior (OCB) of teachers: Proposing a modified social exchange model. ProcediaSocial and Behavioral Sciences, 29, 1472-1481. 